\title{
Uterine Corpus Rhabdomyosarcoma
}

National Cancer Institute

\section{Source}

National Cancer Institute. Uterine Corpus Rhabdomyosarcoma. NCI Thesaurus. Code C127058.

A rare malignant heterologous neoplasm with skeletal muscle differentiation arising from the uterine corpus. It usually manifests with vaginal bleeding. The prognosis is poor. 